\title{
APUNTES PARA UNA CRÍTICA DE LOS MEDIOS INTERACTIVOS. DE LA DEGRADACIÓN CULTURAL AL EXHIBICIONISMO TECNOLÓGICO
}

\section{Eduardo Giordano $(*)$}

SÍNTESIS: La finalidad de este texto es ilustrar acerca de algunas tendencias y enfoques sobre el papel que desempeñan hoy las tecnologías multimedia y las prácticas culturales interactivas en la educación y en la cultura, con especial acento en sus connotaciones psicológicas y socioculturales. No se pretende realizar aquí un análisis exhaustivo, imposible de llevar a cabo en unas pocas páginas para cubrir un abanico tan amplio de posibilidades, sino de efectuar una somera puesta al día, en cierto modo impresionista, de los horizontes teóricos por los que discurre este conocimiento a mediados de la década del 2000. Tal aproximación, basada en ligeras pinceladas, habrá de desarrollarse, o si es el caso refutarse, en posteriores trabajos dedicados a cada una de las temáticas que en estas líneas apenas se esbozan.

(*) Director de Ediciones Voces y Culturas, Barcelona, España. 


\section{LA DESCRIPCIÓN PSICOLÓGICA DEL «YO INTERACTIVO»}

¿De qué forma afecta a la socialización de los jóvenes el uso de la tecnología interactiva que hoy se promociona como panacea de la llamada sociedad de la información? ¿Es sólo una fuente más de información, o, por el contrario, constituye toda una forma de vida al menos en algunos casos? Vivir compulsivamente conectados a Internet, al mando a distancia, a los videojuegos, imultiplica las interacciones sociales o bien contribuye a diseminar las patologías del aislamiento y de la soledad características de la normalidad que impone nuestro sistema productivo? (Fromm).

Desde la psicología contemporánea, algunos autores advierten que el uso compulsivo de los nuevos medios tecnológicos podría dar lugar a lo que se ha definido como personalidad con un «yo interactivo», o, de un modo más impreciso, a una persona de carácter binario. Estas denominaciones serían equivalentes a la noción más habitual de videoadicto, entendiendo por tal a quien ha perdido contacto con la realidad externa y la ha suplantado en parte por la interacción con la máquina informática, la cual ha sido internalizada «como modelo en la realidad psíquica interna» (Romano, 2000). Aunque en casos extremos esta pérdida de contacto con la realidad se considera característica de psicopatologías como la esquizofrenia o el autismo, dicho autor se cuida de guardar las distancias entre la conducta videoadictiva y las alteraciones extremas de la personalidad. A diferencia de ellas, el videoadicto podría interactuar eficazmente con la realidad para sus fines de socialización (utilitaria) y los reproductivos, pero sin conseguir interacciones sociales que le permitieran su realización afectiva como ser humano.

«Estas personas han perdido las identificaciones básicas de su vida psíquica, e intentan sustituir este vacío con las imágenes y las figuras de la pantalla. El yo interactivo obtiene de la computadora y del televisor frágiles identificaciones restitutivas de ese agujero interior [...]. Las imágenes telemáticas, Internet y los videojuegos cumplirían para los caracteres binarios y los videoadictos la función de apuntalar este marcado deterioro de su identidad» (Romano, 2000).

El acceso fragmentario y entrecortado a los mensajes y a los contenidos liberaría al individuo interactivo de todo anclaje en profundidad. Su cotidianidad se definiría por la continua sucesión de movimientos, sin un hilo conductor más allá de la inmediatez del deseo o de la obligación laboral. Los poseedores de ese yo interactivo que describe 
Romano ${ }^{1}$ son, en general. personas que hacen un esfuerzo de sobreadaptación al entorno, que carecen de vínculos genuinos con los demás, a quienes en el fondo desdeñan, que consideran que el tiempo es oro, y que se atrincheran en una creciente inercia emocional:

«Propongo que aquello que denomino Yo interactivo o carácter binario, constituye un subgrupo de las Ilamadas "patologías del vacío" y "estructuras tóxicas" (investigadas por A. Green y D. Maldavsky, respectivamente) y que surgen en el contexto de las videoculturas» (Romano, 2000).

La práctica delzapping, uno de esos «contextos de estimulación desbordante» a los que alude Romano, junto con las redes telemáticas, los canales de televisión por cable y los locales de videojuegos, estarían abriendo paso a otra clase de yo, casi anónimo, fundado en espejismos y en pantallas, que interactúa en términos de relaciones de proximidad, de velocidad, de sucesión y de fugacidad. Al relegar a un segundo plano el juego genuino - con toda su carga de simbolismo- como espacio de transición entre la realidad y la fantasía, el niño se aleja del lugar virtual que posibilita el ensueño, la capacidad de ilusión y la elaboración de sus propias fantasías. Estos estímulos de los procesos naturales de aprendizaje quedarían sumergidos en escenarios virtuales, con sus correlatos de fascinación (hipnótica) y de confusión.

Ahora bien, la cuestión de las posibles narrativas a través de los nuevos medios es lo que más deslumbra a los productores y a los evaluadores de contenidos. Los contextos de interactividad sugieren la superación de las formas lineales de narración propias del soporte papel y/o de la película, y surgen expresiones tales como arte post-cinematográfico o post-televisión para designar a los videojuegos, y, en general, a todos los llamados cibertextos, que, en virtud de su carácter interactivo, representarían la forma más vanguardista de comunicación social. No es

\footnotetext{
${ }^{1}$ En nuestra opinión, la noción del yo interactivo requiere mayores precisiones. ¿Existe algún yo que no lo sea, que no interactúe de una manera u otra? ¿Se es interactivo sólo cuando se interactúa con una máquina y a través de una pantalla (vídeo, Internet, mando a distancia), y no cuando se interactúa directamente con personas? Para el autor de este concepto, es sólo interactivo el yo de todo aquel que interactúacompulsivamente con los nuevos dispositivos tecnológicos como forma de huida del mundo real. Pero muchos no aceptarían esta definición, ya que la interacción humana precede en el tiempo y como concepto a la idea que hoy tenemos de interacción con la máquina. Sin embargo, este uso particular del yo interactivo estaría muy cargado de la última acepción de la interacción, excluyendo las formas previas y lindando más con las características psicológicas del individuo hiperactivo.
} 
extraño que estas teorizaciones se produzcan, por ejemplo, en el contexto de unas jomadas profesionales denom inadas Metanarrativas', en las cuales, a pesar de la ambigüedad críptica del término que les da título, se pretende analizar la especificidad de los metarrelatos interactivos en relación con las narrativas tradicionales, literarias o cinematográficas.

\section{2. ¿APOCALÍPTICOS O INDIVIDUOS VIRTUALES?}

La idea de un yo difuso y sin un fuerte anclaje interior es comúnmente aceptada, si bien con otras connotaciones, por muchos productores y difusores de contenidos para las nuevas tecnologías multimedia. La búsqueda de un barniz de trascendencia para justificar de manera artística determinadas propuestas de la industria cultural en formato multimedia, en particular de la industria de los videojuegos y de Internet, conlleva la asunción implícita del carácter evasivo del modo de vida que estas actividades posibilitan y en gran medida estimulan, reapropiándoselas en un intento de positivización de las críticas de sus detractores.

Desde la perspectiva de los actores más comprometidos con la difusión teórica y práctica de las producciones y/o con los productos de la realidad virtual, la fragmentación digital puede ser elogiable porque «no es una fragmentación como la del mundo físico», tal como escribe una periodista española especializada en la web de su periódico. Por ello, las comunidades virtuales y el arte o la cultura basados en la tecnología se moverían en el nivel de "las cosas que todavía no tienen ningún nombre. Son metacosas, metarrelaciones, metanarrativas, metavida yun metamundo que no podemos explicar. Quizás ya no podremos nunca» ${ }^{3}$.

Si esta gran confusión de conceptos es la actitud intelectual que predomina en el discurso de quienes aparecen como más implicados en el universo de la comunicación telemática, puede decirse que hay, además, una ideología del meta-yo autosatisfecho, precisamente en la dirección que apuntaba Romano al referirse al yo interactivo. En las redes

2 Jornadas Metannarativa(s)? 2005 - 5a J ornadas sobre arte y multimedia, Caixaforum, Barcelona, 28 y 29 de enero de 2005 . (Esta parte de nuestro relato se basa en las ponencias presentadas por investigadores y por realizadores de videojuegos en el marco de dichas jornadas).

${ }^{3}$ Mercè Molist: «El meta-yo», en comunicación presentada a las Jornadas Metanarrativa(s)? 2005 
virtuales uno ya no es uno mismo, sino la representación y/o la simulación de sí mismo que ofrece en la red a los otros, de quienes con frecuencia también desconoce su verdadero yo.

Así también lo conciben otros autores que no siempre dan a este hecho una connotación negativa. Por ejemplo, en el texto que reproducimos a continuación:

«Suspendidas las garantías de una realidad como marco de referencia del discurso, como constatación entre el decir y el hacer, los individuos que se comunican por Internet hacen algo más que transmitirinformación, de alguna manera se ficcionalizan, ingresan al mundo del otro y presentan su propio mundo desde el espacio de la escritura, lo cual supone el ejercicio de una determinada narrativa y la inscripción de la palabra en un género específico» (Davalle, 2003).

Así, por el análisis de lasnarrativas personales, también podríamos acceder al mundo de las representaciones mentales de los propios actores implicados en difundir el conocimiento de los medios interactivos, si bien por la puerta trasera:

"Con cada mail que escribo, cada web que visito, cada vez que "hablo" en un weblog, construyo mi personaje, mi ego virtual, un yo que va más allá del yo. Me lo creo si los otros se lo creen, pero no es real; es, soy, mi creación. Me convierto así en artista de mí misma [... . En el mundo virtual somos escritores de la propia vida, pero no de la auténtica, no es una biografía sino una obra de ficción, la que cada uno se construye de sí mismo».

Este deslumbramiento por la impostura autobiográfica que posibilitan algunos medios interactivos contrasta con la ceguera sobre sus implicaciones en ciertos patrones de conducta patológica. No negamos la posibilidad de que todo eso pueda tener, en determinados casos, un sano componente lúdico que no implique la negación del verdadero yo; pero esta es sólo una de las posibilidades implícitas en dicha clase de discursos, no la única. Frente a la exaltación ciega de la irrealidad, desde el enfoque más crítico en relación con la llamada cultura digital, se plantea la problemática de la adicción a unos medios tecnológicos que fomentan la fragilidad perceptiva, y que conllevan una sobreabundancia de estímulos que dificulta el pensamiento genuino por

${ }^{4}$ Ibídem. 
la imposibilidad de reflexionar, de estar a solas con uno mismo, y, en suma, por la dificultad de pensar en ausencia de ese flujo de estimulación externa.

Tal vez al gunas de las formulaciones críticas de Romano puedan resultar demasiado extremas o precipitadas (el yo interactivo no piensa), a menos que se comprendan y se compartan del todo los conceptos psicológicos que desarrolla el autor. No obstante, como en el caso de muchas otras adicciones, parece clara su explicación de la motivación que late en la conducta de todo videoadicto: «la adicción a Internet tendría la función de colmar un vacío subjetivo» (Romano, 2000).

\section{PROBLEMAS CONCEPTUALES Y TRAMPAS LINGÜÍSTICAS}

En el plano exploratorio de la búsqueda de definiciones para lo más novedoso, siempre aparecen incontables trampas lingüísticas. Por ejemplo, en el contexto de las comunidades que se conectan a través de Internet, resulta dudoso el uso que suele hacerse de la expresión comunidad virtual aplicada a un conjunto de personas que se comunican a distancia en función de intereses comunes, y que de hecho constituyen una comunidad real aunque alejada físicamente, tal como podrían estarlo, v. gr., los miembros de cualquier asociación de ámbito nacional o internacional, con independencia del medio a través del cual se comuniquen.

Cuando el medio de comunicación, en este caso el de funcionamiento en red, es lo que define a un agrupamiento humano, se corre el riesgo de extrapolar las denominaciones tecnológicas al plano de las definiciones sociales, lo que a menudo es un contrasentido (Giordano, 2003). No hay ninguna comunidad de personas reales que no sea una comunidad real, a diferencia de lo que entendemos por realidad virtual, diseñada por medios informáticos, es decir, imaginaria.

De igual modo, se confunden los soportes léxicos de los conceptos (y éstos se emborronan cada vez más) cuando la idea de virtualidad aparece aplicada a la posibilidad de realización de un mensaje (ya sea un breve e-mail o un extenso hipertexto) cuando dicho mensaje se transmite en formato electrónico. Aunque tales sean las condiciones básicas de materialización de la tecnología multimedia, poco tienen que ver con el carácter real o virtual de la comunicación. ¿Acaso diríamos que una 
Ilamada tel efónica, por el hecho de transmitirse a distancia, es una forma de comunicación virtual? ¿Por qué debería serlo entonces un foro realizado a través de Internet? Tal vez podríamos Ilamarlo de esa manera si sus participantes fueran desconocidos entre sí en la realidad, y algunos o todos ellos se autoasignasen personalidades virtuales, es decir, imaginarias. De lo contrario, en el caso de un simposio científico convocado a través de Internet, hablar de comunicación virtual y de comunidades virtuales sería un auténtico contrasentido.

Otro ejemplo de trampa lingüística es la apropiación de prefijos o de sufijos de origen humanístico para elucubrar teorizaciones tecnologicistas extremas. Así, v. gr., en las citadas jornadas sobre Metanarrativa(s), el solo título de las mismas es una invitación al pensamiento ambiguo. El coordinador de las jornadas nos invitó en su presentación a participar en un metadebate, a la vez que explicó que la expresión metanarrativa(s) tiene poco que ver con lo que se encuentra en Internet bajo la denominación de metanarrativa, aplicado sobre todo al «discurso postmoderno original (principalmente de Lyotard, en 1984, cuando define postmodernidad como incredulidad respecto de las m etanancativas) $\gg^{5}$. Hay pues, en este uso indiferenciado del lenguaje, un gesto de rebelión contra otro uso indiferenciado anterior: el de los teóricos de la postmodernidad. Se trataría entonces de un doble salto al vacío, porque, al fin y al cabo, ¿qué son las metanarrativas?

«Lo entendemos como un cambio de lugar, de forma, de condición a fin de ir hacia una situación de posterioridad, de más allá, de aplicación del prefijo meta en el sentido de "después", al estilo de como siempre se ha entendido que la metafísica viene después de la física [...]. Se puede interpretar como una metamorfosis de la noción de narratividad».

Se trata de una metafísica, de un relato verosímil en el plano discursivo, aunque sin fundamento lógico, centrado en las relaciones entre narratividad y medios tecnológicos, de unas relaciones basadas en la discontinuidad de la narración para dejar lugar al componente interactivo. Como muchas disquisiciones postmodernas, esta parece un callejón sin salida que no lleva a ninguna parte más allá de los fuegos de artificio lingüísticos. Más sofisticado es el punto de vista que se permite subrayar las contradicciones entre la narratividad y la llamada ficción

\footnotetext{
${ }^{5}$ Antoni Mercader: «Invitación a un metadebate», coordinador general de las jornadas Metanarrativa(s)? 2005
} 
variable (o intervencionista), que se produciría cuando la narración no está basada en unos personajes sino en unas acciones, con lo cual la interactividad es la externalización de la causalidad. Aquí la idea de fragmentación y de disolución de las narrativas aparece con un sesgo mucho menos favorable:

«La principal dificultad de las ficciones digitales es su aspecto entrecortado, fragmentario, laberíntico. Este aspecto disperso es el argumento más convincente contra la "ficción interactiva", ya que esta dispersión no proviene en principio de un motivo ficcional sino de un motivo técnico, que es la ruptura entre la acción y la reacción del ser humano y del ordenador, un quiebre de la misma causalidad» ${ }^{6}$.

En general, las referencias más frecuentes de los teorizadores de los medios interactivos y del arte digital se cifran en alusiones a los filósofos postmodernos, o, más precisamente, a los teóricos de la postmodernidad, entre los cuales destacan los autores de trillados discursos sobre el final de las viejas narrativas. En su concepción efímera del presente, introducen como nociones centrales de nuestro tiempo ideas que prefiguran las formas discursivas de los nuevos medios; por ejemplo, las nociones de fragmentación, de aceleración del tiempo (tendiendo un puente hacia la llamada cuarta dimensión temporal de algunos discursos teóricos del arte tecnológico), de disolución y/o de imprecisión de los contornos de los lugares físicos y de las fronteras.

Algunos teorizadores (y artistas teorizadores) del arte digital han dado cuenta de la influencia de autores como Paul Virilio, Gianni Vattimo, J acques Derrida, Félix Guattari y otros filósofos considerados como postmodernos (entre los que nunca deja de citarse a Michel Foucault, pese a las enormes distancias teóricas que lo separan de los antedichos) en las obras de arte digital que ellos mismos producen 0 admiran. Estas referencias se hacen del todo explícitas en algunos ensayos ${ }^{7}$, mientras que en muchos casos es en las obras donde se actualizan de forma constante. No es objeto del presente trabajo juzgar los resultados o la validez de dichas nuevas propuestas ${ }^{8}$, con frecuencia

${ }^{6}$ Gregory Chatonsky: «Qu'est-ce que la fiction variable?», en J ornadas Metanarrativa(s)? 2005.

${ }^{7}$ Ver, por ejemplo, el texto de Rodrigo Alonso titulado «Esto no es un aviso publicitario: Un ensayo sobre la obra de Antoni Muntadas en vídeo e Internet», en J . La Ferla (comp.), 1997.

${ }^{8}$ Hay un inmenso campo de experimentación abierto en el Ilamado arte digital o interactivo, basado por lo general en las técnicas narrativas del hipertexto y en la 
muy ambiciosas y difíciles de evaluar de manera genérica, sino intentar una aproximación a la filosofía subyacente en esa nueva corriente artística y a sus interrelaciones con la práctica artística que cristaliza a través de los nuevos medios tecnológicos. La reivindicación de la banalidad como posible apariencia de la expresión artística o como actitud complaciente de la producción intelectual, encuentra asidero desde una posición filosófica en la que se diluye la pertinencia axiológica de todos los conceptos en un magma indiferenciado, es decir, en la medida en la que se rechaza la preeminencia de algunos valores sobre otros como postura ética del individuo.

El problema de tales filosofías evanescentes es que pierden de vista cómo se constituyen en la realidad las vivencias del individuo y las de sus relaciones sociales. Desde la crítica al postmodernismo como actitud intelectual (estudios sobre la deconstrucción de Derrida y otros autores), y también contra la pretensión científica de ciertos estudios culturales, otra perspectiva epistemológica sitúa los viajes ciberespaciales en una dimensión real:

«No se está en el ciberespacio, ni en los mundos virtuales: se habita en un territorio como "base" aunque uno se desplace desde allí hacia otros permanentemente. Y cuando se está en otros, se sabe siempre cuál es aquel que opera como el lugar "desde el cual" vamos [...]. No existen las identidades nómadas y absolutamente desterritorial izadas que al gunos autores imaginan» (Follari, 2003).

Este autor nos recuerda que «la identidad implica un anclaje» del propio yo, y que es imposible comprender la naturaleza de las interacciones del individuo si apenas lo consideramos en disolución en el flujo de comunicación de la red.

En las consideraciones críticas de los usos de los videojuegos y de Internet, se aprecia con frecuencia un deslizamiento en cierto modo

\footnotetext{
tecnología informática desarrollada con recursos multimedia (tanto a través de Internet como de su almacenamiento en otros soportes), que permite una recepción participativa por parte del consumidor o del observador. Desde mediados de la década de 1990 momento en el que se empieza a hablar con insistencia de una crisis en el mundo de los pioneros de la videocreación (que parecían haber llegado a un callejón sin salida desde sus inicios en los años setenta), el arte digital, el arte informatizado, también empieza a considerarse entre las vanguardias de la época como un soporte adecuado para proseguir la experimentación con el medio videográfico, sumado a otros medios e interactuando con ellos.
} 
fetichista hacia el propio medio tecnológico en el desarrollo de conceptos que buscan definir sus implicaciones psicológicas y socioculturales. Así, se habla con naturalidad de la cultura digital, y, aún más extrañamente, de cultura binaria, para expresar lo que con objetividad sería más apropiado llamar, a lo sumo, cultura cibernética.

Del mismo modo, el aprendizaje mediatizado por las máquinas y por las redes informáticas suelellamarse aprendizaje virtual, indicándose que es una modalidad característica de la era digital, pero advirtiendo que la virtualidad reside no tanto en el soporte como en el tipo de interacción que se establece por la forma de presentación de los contenidos a través de pantallas ${ }^{9}$. Si la clave del concepto de aprendizaje que se pretende definir está dada por las formas de interacción, ¿no sería más apropiado referirse al aprendizaje interactivo (real, antes que virtual)? Tanto más cuando este autor considera un «casi pleonasmo» el uso de expresiones tales como herramienta mediacional. Pero el uso del aprendizaje virtual se ha impuesto desde hace años en la bibliografía internacional sobre estos temas, sobre todo en la literatura anglosajona, yel mismo autor español que lo utiliza reconoce su deuda con los trabajos de Schank (1997) y de otros autores que lo emplearon con anterioridad, precursores también en el diseño de programas educativos para la enseñanza a distancia (e-learning).

Cuando aún no está claro a qué aluden con exactitud muchos autores al hablar de hipertexto (contenidos textuales no lineales, textos intercalados con otras formas de presentación, etc.), aparece en el escenario un nuevo término, el de cibertexto, con la pretensión de diferenciarse por completo de aquél. Las definiciones propuestas por los expertos no siempre facilitan nuestra comprensión: « un cibertexto es una máquina para la producción de una variedad de expresiones, literalmente hablando» (Piscitelli, 2002, p 34, las cursivas son del autor). Antes, el propio Piscitelli nos advierte de la existencia de una literatura «ergódica», que se opondría a la lineal, indica que mientras el hipertexto es tributario

\footnotetext{
9 «Para nosotros "aprendizaje virtual" es una expresión más amplia que el aprendizaje a través de Internet, e incluye todas las formas de aprendizaje que están mediadas informáticamente. La virtualidad es un resultado de la herramienta de mediación, que actualiza los contenidos, de manera interactiva, en pantallas. Es la estructuración de los contenidos y de las formas de interacción y de comunicación lo que a nuestro juicio constituye el problema más interesante, independientemente del soporte o del medio de transmisión» (Rodríguez Illera, 2004).
} 
de lo ergódico estático, el cibertexto entraría en el campo de lo ergódico dinámico (videojuegos, programas educativos) ${ }^{10}$.

Toda la nebulosa del vocabulario de inspiración tecnologicista no siempre implica asumir la determinación tecnológica de los procesos de aprendizaje o de los formativos. Interrogarnos por la pertinencia terminológica no supone menoscabar los valiosos desarroll os conceptuales de quienes usan tales términos como palabras-símbolo. Por el contrario, con frecuencia ocurre que los propios análisis de los autores acaban demostrando los límites de esta terminología ambigua, y de al gún modo se revuelven contra ella.

Si en muchos casos las explicaciones de cómo actúa la tecnología informática en los procesos cognitivos y en general de aprendizaje se nos presentan como oscuras, mucho más sombrío es el intento de transponer la operativa informática a las formas de pensamiento conocidas, como si el funcionamiento de la máquina pudiera (y debiera) ser emulado por la mente humana. Este es el caso de un autor-gurú citado por Piscitelli, David Kolb ${ }^{11}$, un filósofo que sugiere que el estudio de las técnicas hipertextuales permitiría modificar los estándares de la argumentación lógica, para producir unas formas de pensamiento y de especulación filosófica no lineales.

La precariedad es lo que más ha caracterizado hasta ahora a la mayor parte de las indagaciones teóricas destinadas a generalizar los usos sociales de las tecnologías llamadas interactivas, no tanto en las prácticas directas que emanan del ámbito educativo como en los enfoques pretendidamente sociológicos, filosóficos y epistemológicos del tema. Muchas aportaciones nos recuerdan la deuda teórica con McLuhan sobre un modo de ver los medios que prescinde del análisis de las relaciones sociales implicadas en los distintos usos tecnológicos. La euforia tecnologicista a veces desemboca en lo esotérico, como cuando se afirma que un sistema de conferencias electrónicas puede servir para abolir el tiempo y el espacio, y se establece un paralelismo entre esta tecnología y la percepción extrasensorial (Piscitelli, 2002).

\footnotetext{
${ }^{10}$ Esta interpretación se basa en Ios trabajos de Espen Aarseth, autor de Cybertext. Perspectives in Ergodic Literature.

${ }^{11}$ Autor de un disquete de hipertexto tituladoSocrates in the Laberynth, editado por Eastgate Systems.
} 
¿Hay vida más allá de Internet? Esta pregunta parece haber dejado el registro de lo humorístico para extender sus posibilidades a la cuestión original que está en su nacimiento: ¿hay vida más allá de la Tierra? Desde una perspectiva epistemológica difusa, asentada sobre las arenas movedizas del pensamiento postmoderno atravesado por los estudios alturales, es posible pensar enunametacultura, que, a partir de las potencialidades de Internet, pudiera dar cabida al pensamiento esotérico de una xenología en la que el Otro no se define por sus características étnicas o socioculturales, sino por su pertenencia a una potencial civilización extraterrestre (Piscitelli, 2002). El deslumbramiento por la pseudociencia desarrollado con presupuestos que no esconden sus finalidades (militares) y sus objetivos más inmediatos (de control social), enceguece la mirada epistemológica desde la que se pretende conferir un estatuto de validación a los viejos temas esotéricos. Si desde la epistemología educativa o desde la investigación sociológica se sugiere la posibilidad de explicar el funcionamiento de los nuevos medios tecnológicos mediante derivas que se adentran en los misterios del contacto con posibles alienígenas, es que algo no va muy bien en al gunos medios académicos. Tanto más si se adopta como inspiración de tales explicaciones el desarrollo del curioso programa de Búsqueda de Inteligenciatre (BIE, SETI en inglés) ${ }^{12}$, que recibe su principal financiación de la Secretaría de Defensa de Estados Unidos.

Conceder el estatuto de saber científico a estas divagaciones ya es un desconcertante problema epistemológico. Pero además, en palabras del citado autor, cumplir con los objetivos de tal programa exigiría «una desantropomorfización de la experiencia, al intentar pensar la alteridad más radical que pueda presentársenos a los seres humanos» (Piscitelli, 2002). En las estridencias de este discurso, según el cual la teoría de la información podría servir como modelo para la decodificación de los primeros mensajes extraterrestres que en el futuro recibiéramos los humanos, se advierte un cierto contagio de la ficcionalización que nos prometen como panacea de las narrativas de los nuevos medios, junto con la falta de rigor y con la inconsistencia teórica de un gran número de aportaciones pseudocientíficas que pretenden dar cuenta de cómo afectan a la humanidad los más recientes desarrollos de las Ilamadas ciberculturas.

\footnotetext{
${ }^{12}$ Search for Extraterrestrial Intelligence ( SETI).
} 


\section{VIOLENCIA SIMBÓLICA, VIDEOJUEGOS Y COMPORTAMIENTO JUVENIL}

Los videojuegos ya no son un novedoso accesorio de la cultura de masas, como se los podía considerar una década atrás, pues en los últimos años se han convertido en una de las principales fuentes de ingreso de las industrias culturales y del entretenimiento. Un videojuego por demás polémico lanzado para la consola Play Station 2, el San Andreas (GTA), consiguió hace poco mayor recaudación que todos sus predecesores, superando incluso las cifras de las producciones cinematográficas y discográficas de más éxito en un período muy breve (campaña de Navidad). En sólo dos meses (noviembre y diciembre de 2004) se vendieron en todo el mundo 32 millones de ejemplares (medio millón en España $)^{13}$.

Hace ya algunos años el ritmo de crecimiento de este negocio lúdico ha llevado a la principal multinacional de software del mundo, Microsoft, a producir su propia consola de videojuegos para entrar con mayor fuerza en la competencia internacional por este segmento del sector del entretenimiento. Otras compañías informáticas, entre las que destaca Apple, han dado distintos pasos en la producción de equipos y en la distribución de contenidos de la industria musical o de diferentes productos multimedia. Los proveedores tradicionales de productos informáticos han comprendido que la forma más eficaz de remontar el estancamiento en las ventas de sus artículos consiste en redirigir la estrategia de mercado para captar a los jóvenes consumidores de la cultura de masas en sus más variados formatos, al igual que ocurre con el nuevo salto de la telefonía hacia la integración de los equipamientos móviles con la red interactiva y con la grabación y transmisión de imágenes.

Casi todos los videojuegos recurren a la violencia como principal argumento de las interacciones entre el jugador y la máquina. Este es el caso del ejemplo que ya comentamos, pero también el de la totalidad de sus predecesores más exitosos ${ }^{14}$. Otros juegos también

\footnotetext{
${ }^{13}$ Según datos del sector, con una facturación de 800 millones de euros en 2003, la industria de los videojuegos ya supera en España los ingresos de otras formas de ocio tradicionales, tales como la industria cinematográfica ( 636 millones) o la discográfica (550 millones). El núcleo de consumidores regulares de estos productos estaría formado por siete millones de personas, sobre todo niños y jóvenes (EI País, 9/I/2005).

${ }^{14}$ Carmaggeddon, Manhunt, Postal, etcétera.
} 
tienen implicaciones políticas, como es el caso de Ghost Recon 2 (sobre Corea del Norte), Counter Strike (juego de acción on-line de policías contra terroristas), September 12 th (videojuego gratuito ejecutable a través de Internet, que permite arrojar misiles sobre poblados afganos cuyos supervivientes se convierten en terroristas), y los llamados J uegos colombianos de guerra ${ }^{15}$, a los que su propio creador, J uan Ospina (hijo de un comandante antiguerrillero del ejército de Colombia) considera juegos macabros e impactantes. $Y$ en realidad lo son, en particular el juego Masacre paramilitar, presentado como una «lucha contra el reloj mientras acabas con los simpatizantes de la guerrilla en el pueblo». EI juego comienza preguntando al compatriota si conoce los objetivos de su labor, que de manera escueta se expresan así: «Debes encontrar y ejecutar a los simpatizantes de la guerrilla para completar la misión». EI jugador no tiene más opción que avanzar con las flechas y disparar contra la población civil indefensa hasta el exterminio total de los habitantes del pueblo, contando con el estímulo de un cronómetro que calcula cuánto se tarda en consumar la masacre. Cada persona contra la que se dispara se convierte en una cruz plantada en el suelo. ¡A esto se reduce la interacción que permite el juego!

Otros videojuegos a los que se accede a través de Internet tienen, además, un lamentable contenido racista. Por ejemplo, uno Ilamado Acción gitana, que consiste en elegir armas para proceder a la limpieza étnica de gitanos de todo un país, en este caso Hungría. Tal juego fue retirado de la red gracias a la presión de organizaciones defensoras de los derechos de los romaníes húngaros.

En un plano menos ideológico y mucho más comercial, los creadores de videojuegos admiten que, en general, predominan los juegos interactivos violentos por razones de mercado. En el propio sector se considera que el $98 \%$ de los videojuegos es de contenido violento, porque eso es lo que exigen las empresas productoras (cada vez más enmarcadas dentro de grupos multimedia o dependientes de compañías informáticas y/o de electrónica). Estas, a su vez, achacan tal hecho a las tendencias de la demanda, es decir, culpan a los usuarios, en su mayor

${ }^{15}$ Con títulos tan expresivos como Ataque con pipeta de gas, Masacre paramilitar, etc. Según declara el autor en una página de presentación a la que se accede de forma independiente de los juegos, éstos «sólo quieren ilustrar una realidad y preguntar: ¿de verdad el fin justifica los medios?». Pero, ¿cómo alguien que asume el papel de un paramilitar y se entretiene disparando cada vez más rápido contra la gente podría formularse semejante pregunta? 
parte niños; un argumento al que ya estamos acostumbrados cuando se trata, por ejemplo, de excusar la mala calidad de la programación televisiva. Pero como casi no existe experimentación sobre otras clases de videojuegos, es imposible saber si otros tipos de juegos gozarían o no del favor de los potenciales consumidores.

En un ejercicio de sofisticación extrema, algunos creadores de videojuegos sugieren introducir una opción secundaria para permitir que el usuario elija si desea resolver los conflictos de un modo pacífico. En cierta bifurcación, el programa dejaría decidir al jugador-protagonista si quiere ponerse a disparar tiros o si prefiere emplear buenas maneras para entenderse con sus adversarios. Pero incluso en el caso de un programa como éste, algo menos condicionante, la balanza se acabaría inclinando casi con seguridad del lado de la acción (violenta), dados los hábitos de consumo que se han ido imponiendo respecto a este tipo de productos.

El problema de la violencia en los videojuegos fue abordado en un informe de la sección española de Amnistía Internacional (AI) titulado «Con la violencia hacia las mujeres no se juega», basado en el análisis de 50 videojuegos de compra y otros 15 de acceso a través de Internet, además de los que se encuentran habitualmente en las salas de ocio. Los responsables de este informe, presentado en diciembre de 2004, aseguran que la mitad de los videojuegos disponibles supone al gún abuso de los derechos humanos y que «atentan contra la dignidad de las personas». Según Esteban B eltrán, director de Al en España, «los videojuegos analizados refuerzan estereotipos discriminatorios y fomentan la violencia contra las mujeres». Los resultados del estudio parecen contundentes:

«En nuestro trabajo de investigación sobre los videojuegos hemos descubierto agresiones a mujeres, asesinatos, violaciones, esclavitud, tortura, prostitución forzada, abuso de menores, tratamiento de mujeres como objetos y otras violaciones de derechos humanos, como la normalización de ataques a la población civil, el desprecio al derecho a la vida e integridad de las personas y la incitación a la violación de los derechos humanos en conflictos armados... y, lo que es peor, los menores de edad pueden acceder a la mayoría de estos juegos sin control alguno, de forma gratuita y por Internet».

Otro reciente estudio sobre los contenidos violentos de los videojuegos fue realizado por la Universidad de León, bajo la dirección de Enrique Díez, basado en el análisis de 250 videojuegos y en la 
realización de 5.000 cuestionarios contestados por jugadores situados entre los 6 y los 24 años. Y un tercero, de la Universidad Complutense, dirigido por Carmen Santisteban, trata el problema desde el punto de vista de los receptores, destacando que los preadolescentes y los adolescentes que pasan horas y horas viendo la televisión son también los que presentan más acusados niveles de agresividad, y se indica igualmente que tal tendencia se produce con mayor firmeza aún entre los que están enganchados a los videojuegos.

Todas las investigaciones ponen de manifiesto las limitaciones de los Ilamados códigos de autorregulación de la propia industria, tales como el denominado código PEGI (Información Paneuropea sobre J uegos), adoptado por las asociaciones patronales del sector de muchos países del área para calificar las edades para las que son aptos los videojuegos. De esta forma, la industria se anticipa -y espera encontrar una escapatoria- a una ulterior calificación de los ministerios de cultura o de otras posibles entidades reguladoras. Además, la calificación a través de estos códigos nunca se cumple en la práctica, ya que no hay mecanismos para impedir la difusión de videojuegos de desarrollo violento y/o sexista entre los niños y adolescentes, ni en los puntos de venta de los productos, ni a través de Internet. En las franjas de edad más temprana se da el agravante del desconocimiento general de los padres sobre el contenido y la orientación de los juegos.

El recurso sistemático a la violencia y a diversas formas de degradación del comportamiento humano como patrón de conducta habitual de los protagonistas de los más exitosos videojuegos plantea un problema sociocultural que trasciende el mundo educativo.

\section{LAS TECNOLOGÍAS DE APRENDIZAJE INTERACTIVO}

La llamada alfabetización electrónica se vertebra hoy en torno a las posibilidades del hipertexto. La tecnología informática permite acceder a una biblioteca ilimitada de textos, de imágenes, de animaciones, de sonidos, de diagramas, de ilustraciones y de otros tipos de datos, que, en conjunto, componen un registro inexplorado de fuentes sobre cualquier tema. Con un enfoque quizás algo idealista, a veces se pone énfasis en la capacidad del lector para armar sus propios recorridos de lectura, y de organizar así una metanarrativa intertextual capaz de generar «significaciones diferentes para cada lectura posible» (Rodríguez 
Illera, 2004). Tal vez esto sea así en el caso de los lectores y de los navegadores más avisados, pero no puede considerarse un camino fácil para los recién llegados a Internet y a las nuevas tecnologías de la información, ni para los niños mientras aún carecen de las más elementales referencias culturales.

En cualquier caso, es evidente la potencialidad del hipertexto como herramienta al servicio del conocimiento. Sin embargo, hay alguna dificultad para saber de qué estamos hablando cuando nos referimos en general al hipertexto. Hipertexto es, por ejemplo, una enciclopedia electrónica que puede consultarse de forma selectiva y que funciona como un solo producto cultural, pero también lo es, en sentido amplio, el conjunto de contenidos (textuales o no) que circulan por Internet. En este último supuesto, el problema metodológico desde el punto de vista educativo es el de cómo abordar contenidos tan amplios e indiferenciados de una manera inteligente y productiva para evitar el llamado efecto mariposa, consistente en la navegación por el ciberespacio de forma aleatoria a través de la infinidad de vínculos o de enlaces que permiten los buscadores, con contenidos no significativos en la mayor parte de los casos.

A esta dificultad se suma el hecho de que el acceso al hipertexto, en sus distintas modalidades, supone una intervención activa del lector, y, por tanto, un grado de interacción que es inversamente proporcional a la posibilidad de darle un sentido lineal al discurso. La misma idea de discurso explosiona en la extrema fragmentación de las partes que caracteriza al hipertexto. Eso supone ventajas en cuanto a la libertad de acceso a la información, pero también implica que la resignificación del texto hipertextual es un procedimiento complejo y laborioso, ya que su sentido no está dado por el diseño de un autor, sino por el itinerario de interacciones que el lector establece con las partes del hipertexto. Considerando la confusión que tales problemas pueden causar a los estudiantes, algunos autores recomiendan tener mucha precaución en los planes de introducción del hipertexto en el ámbito educativo (Rodríguez Illera, 2004).

Rodríguez Illera considera también las posibilidades de aprendizaje que brindan los Ilamados entornos colaborativos, describiendo las rigideces de muchos de esos sistemas y las dificultades que existen para desarrollar una interdependencia genuina entre los miembros de un grupo que dé lugar a un aprender colaborando en un proyecto común a través de una herramienta tecnológica. La exposición de este tema nos 
deja la desconcertante impresión de que el amplio vuelo teórico sobre el que se sustentaría el recurso a dichos entornos no tiene casi ninguna aplicación práctica. Tal hecho no es extraño cuando el propio autor asume que el aprendizaje colaborativo es un tipo de situación mal definida, en la que cabe un número indeterminado de participantes unidos para realizar tareas simples o complejas.

Entre las formas de actividad más concretas de aprendizaje interactivo basadas en la tecnología informática, este autor pone tres ejemplos: una simulación para la enseñanza de la física; el recurso a diagramas cambiantes para representar mapas de conceptos (una técnica que no requiere del todo el uso del ordenador); y un juego de rol para la prevención del Sida. Estos ejemplos, desarrollados brevemente en los anexos del libro, se presentan tras una acertada prevención contra las modalidades que hoy adquiere el e-learning, y, en particular, contra el «exceso de optimismo mal fundamentado, casi mágico, que ha cifrado en la tecnología por la tecnología el fundamente del cambio educativo». Además, añade el autor, las formas de enseñanza a distancia y las semipresenciales no han progresado gracias a la generalización de Internet, sino al contrario: «la tecnología que sustenta los cambios es todavía excesivamente simple como para permitir interacciones verdaderamente complejas con los materiales o formas de comunicación elaboradas [...]. A todo ello ha contribuido el retroceso significativo, aunque sólo desde el punto de vista de la interacción educativa, que ha supuesto la generalización de Internet y las herramientas simples que hoy pueden utilizarse» (Rodríguez Illera, 2004).

Es paradójico que Internet, la herramienta de educación interactiva más importante para al gunos, se considere también culpable de un deterioro de las condiciones de aprendizaje desde el punto de vista de la interacción educativa.

En otro orden de ideas, hay autores que invocan la tradición del pensamiento crítico para cuestionar epistemológicamente diversos aspectos de la aplicación de tecnologías digitales al mundo de la educación. Como posibles antídotos, un autor propone, por ejemplo, «descubrir y denunciar los mecanismos -y las reflexiones- que permiten que las ciencias humanas pierdan su estatuto educativo a manos de un pensamiento reducido a praxis técnica», y «mostrar las intrínsecas limitaciones y el tipo de influencia que contiene la metáfora del ordenador/computador para definir la nueva relación educación-tecnologías digitales» (García Yruela, 2002). 
El desarrollo de este último punto es importante. A partir de la teoría de la información computacional, convertida a través de sus conclusiones en paradigma para la explicación de la realidad, se habría desarrollado la llamada paráfora - paradigma y metáfora- del ordenador: «Puede entenderse por paráfora la figura que relaciona y compara el ordenador con la mente, insinuando - cuando no declarando abiertamente- la prioridad de aquél sobre ésta» (García Yruela, 2002).

Dicha paráfora sería la extensión a los planos psicológico y educativo de esa corriente epistemológica, que, como se ha visto, propone racionalizar la experiencia y el conocimiento humanos según el funcionamiento propio de las máquinas inteligentes. Cuando es posible imaginar cambios en las formas de argumentación lógica que afectarían desde la filosofía y las ciencias sociales hasta las ciencias ocultas, tomando como modelo de razonamiento los procedimientos que desarroIlan las máquinas, ¿por qué no podríamos concebir al ordenador como modelo de funcionamiento de la mente humana? Así quedarían abiertas las puertas al desarrollo de una ciberpsicología capaz de poner muchas cosas en su sitio; por ejemplo, considerar sano y bien integrado al individuo que sólo interactúa con pantallas, rescatándolo simbólicamente de su condición real de videoadicto.

En un punto intermedio entre la crítica feroz y la determinación tecnologicista se encuentra el planteamiento de una lectura crítica, tanto de los contenidos como de los aspectos formales de Internet. Este último aspecto es lo que una autora denomina el código simbólico, con lo que alude al «modo en que se estructura y organiza, simboliza y distribuye» el conjunto de contenidos que circula a través de Internet, así como al uso de la red que hace el usuario en un determinado contexto histórico-cultural (Fainholc, 2004). En tal sentido, además de la interactividad y de la hipertextualidad, aparecen como características de las formas de comunicación de Internet la conectividad y la intertextualidad. Por conectividad se entiende la posibilidad de acceso reticular (en red de redes) a un caudal ilimitado de contenidos. Dicha característica permite la interactividad remota que requieren los nuevos métodos de educación a distancia. La intertextualidad se refiere al conjunto de relaciones que un texto establece con otros; por ejemplo, a través de enlaces en el caso de Internet. Cada uno de estos textos existe como discurso autónomo, y, según su articulación conjunta, «resultan en procesos que construyen significados (o semiosis) diferentes» (Fainholc, 2004). 
Desde esta perspectiva, la función primordial del educador es la de capacitar al estudiante para utilizar los recursos comunicacionales de la manera más fructífera posible en la vida real. Si en la red caben toda clase de discursos, no se trata de demonizar su uso por la dificultad para acceder a contenidos significativos, sino de democratizar su potencial a través de un entrenamiento consciente en el dominio de los mecanismos de búsqueda afinada de información (filtros, etc.) y de validación de los datos hallados según el tipo de página que se consulte. Una prolongación natural de este enfoque sería superar la fase de lectura crítica para orientar al estudiante en la dimensión productiva de la transmisión de contenidos, estimulando su habilidad de comunicar información a través de las nuevas tecnologías.

\section{BIBLIOGRAFÍA}

DAVALLE, V. (2003): «Señor, ¿usted habla de información?», en Zátonyi y otros: ¿Realidad virtual?, Buenos Aires, Nobuko.

FAINHOLC, B. (2004): Lectura crítica de Internet. Análisis y utilización de los recursos tecnológicos en educación, Rosario, Homo Sapiens.

FollaRI, R. (2003): Teorías débiles. (Para una crítica de la deconstrucción y de los estudios culturales), Rosario, Homo Sapiens.

Fromm, E.: La patología de la normalidad, Barcelona, Paidós.

García Yruela, J. (2002): «Educación-Cultura-Tecnologías digitales de la información: hacia una relación crítica y eficaz», en Educación para la comunicación. Televisión y multimedia (libro interactivo), Máster en TVEducativa, Madrid, UcM-Corporación Multimedia.

GIORDANO, E. (2003): «El “laberinto” tecnológico y las nuevas formas de control social», en Revista Científica de Información y Comunicación, $n .1$ 1, Sevilla, Universidad de Sevilla.

LA FERLA, J . y otros (1997): Contaminaciones: del videoarte al multimedia, Buenos Aires, Eudeba-Libros del Rojas.

PISCITELLI, A. (2002): Meta-Cultura. El eclipse de los medios masivos en la era de Internet, Buenos Aires, La Crujía Ediciones.

RODRÍGUEZ I LLERA, J . L. (2004): El aprendizaje virtual. Enseñar y aprender en la era digital, Rosario, Homo Sapiens.

Romano, E. (2000): La cultura digital, Buenos Aires, Lugar Editorial.

SCHANK, R. C. (1997): Virtual Learning, Nueva York, MacGraw-Hill. 